\title{
Inheritance and Application of Traditional Culture in Game Clothing under the Background of Digital Art*
}

\author{
Xiaoli Yu \\ Faculty of Clothing and Design \\ Minjiang University \\ Fuzhou, China 350108 \\ Fujian Provincial Design Center for Fashion Industry \\ Minjiang University \\ Fuzhou, China 350108
}

\author{
Jiangang Wang \\ Faculty of Clothing and Design \\ Minjiang University \\ Fuzhou, China 350108
}

\author{
Liangzheng $\mathrm{Yu}$ \\ Faculty of Clothing and Design \\ Minjiang University \\ Fuzhou, China 350108
}

\begin{abstract}
This article discusses the value and significance of game clothing to inherit traditional culture, then based on two home-made games, it analyzes the cultural connotation that the clothing of typical characters carriers, finally it describes the approaches to apply traditional in the game clothing design so as to stimulate the life force of traditional culture in modern digital art and realize the dynamic inheritance of traditional culture.
\end{abstract}

Keywords-traditional culture; game character; clothing design

\section{INTRODUCTION}

Going with the rapid development of IT (information technology), electronic game industry, guided and promoted by serial state policies, has taken on a huge potential for development, which has become one of the most attractive, influential and valuable fields. In a virtual work created, each game character has characteristics of its own, and the clothing with diverse features brings up-and-down plots, guaranteeing the interesting and attraction of games. More and more people start to chase after electronic games and raiser higher requirements to the clothing of characters, yet the clothing design of characters in home-made games still need to be improved, main problems include, more attentions are paid to functions yet little to personality and feature, besides, most have no cultural connotation to show[1]. Electronic games are more than an entertainment, it is also an embodiment of artistic forms, excellent game clothing design can not only create full game characters, show elegant game screen but also do good to spread knowledge and culture.

*Porject Fund: Fuzhou science and technology plan project (2016-G79); Social Science Program of Minjiang University (MYS16005)

\section{EXPLORE THE VALUE OF TRADITIONAL CULTURE IN GAME CLOTHING}

In recent years, home-made games have made great leap forward development, which have spread to more than 100 countries and regions, especially the games with traditional Chinese characteristics have attracted eyeballs of players at home and abroad. Game character design of the themes mainly originate from Chinese Kung Fu novels, historical tales or classic literature, supernatural, fantastic and ethnic stories and so on, which can not only increase the mystery of games but also bring resonance to players in spirit, such as Journey to the West and Romance Three Kingdoms of the four famous works, with the well known stories as game structure, plus diverse amazing elements, players may have their senses of identity increased. For example, after changed to new schools, Kung Fu novels have developed rapidly, which not only carry symbols of traditional Chinese culture but also are popular in domestic people, influenced by the point, some home-made games are full of supernatural and Kung $\mathrm{Fu}$ characteristics, the characters are real, who are strong and powerful, and dynamic characters are stressed, besides, their clothing design also embodies thick cultural deposits.

China has a cultural history of more five thousand years, during the long term development, there are diverse wonderful stories, classic and legendary characters, and there are countless elements that can be used in game clothing design. Such elements can be embodied through appropriate methods, relying on electronic games, a digital technology, the post 1980 s, 1990 s and 2000 s will accept the traditional culture that it carries, stimulating the life force of traditional culture in modern society, show the unique charm of traditional culture, achieve the modern inheritance of traditional culture, as such, young people around the world 
are attracted with the international influence of Chinese culture increased.

Animation games in Japan and occident have been taking the lead around the world, which have abundant experience in the game clothing design, they have not only borrowed traditional culture, but also sought to break through and upgrade, which are not restricted to traditional culture. Based on strict game background framework, the conception and creativity of character clothing are fearless and brilliant, but not separated from the main theme, so they are deeply loved by players, which are worth learning.[2] However, the clothing design in home-made games are always traditional, having no great break through, though we have thick cultural foundation, yet we cannot get rid of the traditional restriction for better achievements, therefore, we cannot be restricted by traditional culture any longer.

\section{TRAditional CULTURE EMBODIED IN GAME CLOTHING}

Among the colorful game markets, half of home-made games are occupied by traditional cultural themes such as the Legend of Sword and Fairy, representing the legend of swordsman and the Legend of Three Kingdom rooted in classic Chinese literature and so on. Here this author takes the classic game Fantasy Westward Journey which lasts perpetually and is loved widely and new generation of game The Magic Blade which has unique features and elegant screen as examples so as to explain the cultural connotation that typical character clothing carries.

\section{A. Analysis of Typical Character Clothing in the Fantasy Westward Journey}

The Fantasy Westward Journey is an online game of RPG character playing developed and operated by NetEase Inc, which takes Journal to the West as background, the game characters have three kinds: human being, monster and immortal. Human being mainly include: Jian Xia Ke, Xiao Yao Sheng, Wu Man Er, Fei Yan $\mathrm{Nu}$ and Ying $\mathrm{Nu} \mathrm{Xia}$, for example, Xiao Yao Sheng wears a long gown, whose whole image is gentlemen like but heroic, looking handsome and steady, with a fan and sword carried, he is a learned young man. The character is a unique image owned by Chinese culture, and the graceful appearance can accurately show the personality and background of the character, besides, a black bamboo is designed and left on his clothes, which delivers an atmosphere of gentlemen, in addition, seen from the fan and sword in hand and jade pendant on waist and jewel on the head, he must be famous and noble.

The monsters mainly include: Hu Mei Ren, Gu Jing Ling, Ju Mo Wang, Hu Tou Guai and Sha Po Lang, for example, $\mathrm{Hu}$ Mei Ren is a fox from remote mountains where it has practiced for years, in traditional literature, generally foxes are described as beautiful spirit, so it just goes as this in games, as for the garment color of characters in games, a great number of pink, purple and few white are used, the pink make the character full of temptation, the purple makes it mysterious, the clothing fearlessly adopt modern female underwear styles, with purple gauge added for covering, besides, the gauge makes the character more enchanting, fox fur clothes and metal accessories show the character owns certain position and fighting capacity, and the elements mixing make players feel inconsistent but rational. The weapon is designed to be a rattan willow whip, flowers are fixed on the rattan as decoration so as to clearly indicate the background of the character, making player think of the birth of the character.

The immortals mainly include: Xuan Cai E, Wu Tian Ji, Shen Tian Bing, Long Tai $\mathrm{Zi}$ and $\mathrm{Yu}$ Ling Shen. For example, the image of Long Tai $\mathrm{Zi}$ looks like the combination of Xiao Yao Sheng and Shen Tian Bing, the headwear is a valiant small crown carrying a red big bobbles with a dragon horn on each side, and the clothing is often seen in domestic costume movies and operas for princess, and the whole color adopts yellow representing authority, showing the position of characters. Seen as a whole, it has no extreme difference from other characters, with a character strengthened only.

\section{B. Analysis of Clothing of Typical Characters in the Magic Blade}

The Magic Blade is home-made online game which is based on Chinese styles and combined with traditional literature, it is designed with excellent picture effect and excellent plot. What is the most important is the clothing design of characters that is attractive, it must be a hard work, in the game, each school and career has unique and distinct clothing and decorates, which have made great contributions to home-made games and traditional Chinese culture.

For example, Zhenwu in the game is a character who takes double swords as weapons among eight occupations, the background is set to operate the sword through Qi, stressing the integration of universe and human being, so the clothing design looks domineering, the style is based on long wind coat with collar, and the shoulder, collar and sleeve and lower hem are covered with protective leather armor on which decorative patterns symbolizing the school are engraved, the clothing, made of traditional Chinese silk, the whole modeling is full of Chinese elements, showing the behavior image of the character.

Another example, there is an occupation named beggar gang, which is familiar to us and it can be seen in many literatures and movies, generally beggars are shown in rags, dusty and dirty in appearance. In the game, in order to attract players to feel the charm of the occupation, designers borrow modern garment styles such as suitable inner cloth, wide belt and irregular lower hem, which make the characters do not look dingy, instead, they bring a feeling of laughing, graceful, free and neat, in the meantime, the weapons still adopt classic wine gourd and protective stick, which not only break through the tradition but also make audience accept the leading design with the traditional occupational image remained. 


\section{WAYS TO APply Traditional CULTURE IN THE DESIGN OF GAME CLOTHING}

In order to design characters, first of all, designers need to carefully analyze and study the framework of the game, finding key design inside it, then create distinctive characters through clothing and weapons, make repeated comparison and adjustment on the clothing styles, colors, materials and patterns so as to show the historical background of characters, or describing positions or reflecting personalities of characters. Finally picture composition is based on to conduct a series of clothing design.

\section{A. Design of Clothing Styles in Games}

Clothing styles for characters in games are key for design, seen from the picture composition, the clothing of characters consist of outer shape and inner structure, and the changes of clothing styles are mainly shown on the difference between outer shape and inner structure.

Generally the outer shape is a key for the design, which may directly show characteristics of characters. The outer shape mainly consists of three parts, namely shoulder line, waist line and low hem line.[3] And the tightness between them may create multiple styles, for example type A shape: narrow shoulder, wide lower hem; type $\mathrm{T}$ shape: wide shoulder, tight lower hem; $\mathrm{X}$ type: belted; type $\mathrm{H}$ : straight wide waist. During the actual design of clothing, the changes of outer shape shall make it much exaggerated in time so as to make it more vivid.

Inner structure refers to segmented elements covered by the outer shape, and the key design lies in collar, sleeve, skirt and pants, through changes of inner structures, the character modeling will change as well. The details are important to determine whether the character modeling can succeed or not. Take collars as an example, collars of coat may have collar or not, if carrying collars, it can be further divided into stand collar, turn-down collar and flat-fitting collar and so on. The stand collar can be divided into high collar, medium collar and low collar; if carrying no collar, it can be divided into square collar, round collar, special collar and so on.[4] Similarly, sleeve, skirt and pants can be segmented too, relying on the combination of different details, the inner structure of clothing can be enriched.

\section{B. Color Design of Clothing in Games}

Color is one of the direct factors to determine appearance, which influence invisibly the feeling and mood of the people. The clothing design of characters generally represents personality and relations of characters through colors, for example, upper thick color and down thin color make the character look neat and serious, yet the upper thin color and down thick color make the character look vivid, careful and lively. According to the groups that characters belong to in games, the groups of the characters are designed with main color, through the unique or different colors of clothing, the background position, group cooperation or fights of characters could be shown. For example, in the game World of Warcraft, the clothing of paladin of human being is designed to be white, showing holy and firmness, on the contrary, the clothing of dead knight against them in the game is designed to dark blue, showing withering and coldness.

\section{Design of Clothing Material in Games}

The clothing material of characters in games also help show personalities of characters in games, to which designers should have full understanding and feeling, giving full consideration before selection. Metal and leather materials are hard and heavy, which can be used to represent male strength and stiffness, gauze and feather materials are light and warm, which can be used to represent female blandness and flexibility.

For example, in the game Final Fantasy $X V$, leading actor Noctis Lucis Caelum is designed to be a successor to the throne, young but wondering outside, in the virtual modern world, for the character is compared to light in the night sky, its clothing materials are mostly materials made of elastic leather, thick leather or compound leather, which bring a feeling modern, stiff and tough that man holds. On the coat should and pockets, magnificent and king like designs and badges are decorated, which meet the status of the character who wonders outside. The clothing of leading female actor is represented through material of wedding satin, which look soft and white, showing the female actor is warm and full of hopes to life as well as noble for the character.

\section{Design of Clothing Patterns}

Clothing patterns refer to designs attached thereon, it helps to create a perfect character, making a great success through few efforts. Designers may make use of special designs of Chinese culture to decorate the clothing of characters in games, for example, design of dragons and phoenixes, eight national flowers, Kylin, Chinese ink painting and writing all can well represent traditional Chinese culture, and the characters created have typical Chinese styles.

For example, the character Ju Mo Wang in the game Fantasy Westward Journey is aggressive and powerful, and the clothing design mainly borrows the armors of ancient Chinese generals, yet on the shoulder armor, gloves and belts, devil faces are repeated to make it vicious, fierce and merciless. Another example, the character Wu Man Er, a young girl from witches of a mysterious tribe, who are noble and easy-going, simple and unsophisticated, the clothing design adopts a great number of clouding and spirit, showing her nobleness and more mystery.

\section{CONCLUSION}

Clothing of characters in games is a library, which covers clothing styles in different stages and regions, all are in pursuit of and simulate the fashion from styles and colors that are changing. In the meantime, the clothing of characters also show designers' feeling and understanding of the clothing in different stages and regions as well as an experience of aesthetics in clothing and life. Through imagination and creativity, the feeling and understanding are 
shown on the clothing so as to generate resonance with players in characteristics of characters.

The thick traditional Chinese culture provides rich resources for the design of clothing of characters in games and creation of games with Chinese characteristics, which can not only make characters charming and attract players at home and abroad but also help spread Chinese culture and promote the high speed development of digital art industry.

\section{REFERENCES}

[1] Zhao Caixia, Application of Traditional National Symbols in Clothing Design of Computer Games [D]. Donghua University, 2009.

[2] Gao Ying, Researches on Bases of Clothing Design in Games [D]. Wuhan University of Technology, 2007.

[3] Tang Keqin, Functions and Characteristics of Clothing Design for Characters in Online Games [J]. Art Education Research, 2014,05:106-107.

[4] Lin Hongxia, Li Fujie, Discussion on Computer Games Clothing and Traditional Chinese Clothing Culture [J]. Tianjin Textile Science \& Technology, 2013, 01: 55-57. 